\title{
Rompendo o isolamento: reflexões sobre história oral e entrevistas à distância
}

\author{
Breaking isolation: Reflections on oral history and distance interviews
}

\author{
Ricardo Santhiago* \\ Universidade Federal de São Paulo (Unifesp), São Paulo, SP, Brasil
}

\author{
Valéria Barbosa de Magalhães* \\ Universidade de São Paulo (USP), São Paulo, SP, Brasil
}

\begin{abstract}
RESUMO: O artigo reflete sobre a possibilidade de realização de entrevistas online, conduzidas de acordo com os princípios da história oral. Busca extrapolar a enfatizada discussão técnica sobre as vantagens e desvantagens do uso de entrevistas à distância, empenhando-se em desvendar alguns dos motivos da rejeição ao seu uso e propondo um olhar aberto, e ao mesmo tempo crítico, ao uso deste recurso. Para isso, realiza quatro aproximações combinadas: discussão do lugar ocupado pelo corpo na história oral e em outros recursos de pesquisa correlatos, recuperando a centralidade do conceito de performance na literatura da área; revisão crítica da produção bibliográfica sobre o assunto, apontando suas limitações e conclusôes; ponderações sobre experiências dos autores, extraindo sugestões procedimentais de pesquisas empíricas em ambiente online anteriores; e mapeamento de algumas das iniciativas de discussão e instrução técnicometodológicas surgidas a partir do isolamento social e decorrentes da pandemia da COVID-19.
\end{abstract}

PALAVRAS-CHAVE: História oral. Pesquisa digital. Pesquisa qualitativa.

\begin{abstract}
The article discusses the possibility of conducting online interviews according to oral history tenets. It tries to forward the common technical discussion about the advantages and disadvantages of using virtual interviews, aiming to unveil the reasons for the usual rejection of this tool in most researches, and proposing a more open, though still critical, attitude towards this resource. For that, it performs four combined approaches: considerations about the place occupied by the body in oral history theory and in other related research resources, recovering the centrality of the concept of performance in the field's literature; critical bibliographic review, pointing out its limitations and conclusions; comments about the authors' past experiences, extracting procedural suggestions from previous empirical research in online environments; and mapping of the technical-methodological discussion and instructional initiatives emerged from social isolation that has resulted from the COVID-19 pandemic.
\end{abstract}

KEYWORDS: Oral History. Digital research. Qualitative research.

\footnotetext{
* Professor da Universidade Federal de São Paulo, São Paulo, SP, Brasil. Doutor em História Social pela Universidade de São Paulo (USP), com pós-doutorado em História pela Universidade Federal Fluminense (UFF). E-mail: ricardo.santhiago@unifesp.br. http://orcid.org/0000-0001-5318-5801.

** Professora da Universidade de São Paulo, São Paulo, SP, Brasil. Doutora em História Social pela Universidade de São Paulo (USP). E-mail: gephom@gmail.com. http://orcid.org/0000-0002-6817-4192.
} 
Em outubro de 2014, uma postagem na lista de discussóes da Oral History Association ${ }^{1}$, a associação estadunidense de história oral, pedia o compartilhamento de experiências dos outros participantes a respeito de um tema controverso: a realização de entrevistas à distância, por meio da internet e do uso de suas diferentes plataformas de comunicação para conversas e chamadas em tempo real. A postagem provocou poucas reações, mas todas significativas. Duas respondentes afirmaram terem usado o recurso há pouco tempo, exitosamente (a não ser pelo delay, a demora na chegada do sinal do interlocutor, e da qualidade relativamente ruim do áudio gravado). Outra pessoa disse ter iniciado um projeto com entrevistas conduzidas por estudantes usando o $S k y p e^{2}$, mas se afirmou "[...] particularmente interessada em saber das outras pessoas sobre o que elas acham que muda nas relaçóes, comparando com entrevistas olho no olho, etc." ${ }^{3}$ Não deixa de ser surpreendente que as poucas reações à postagem tenham sido positivas: a discussão especializada em história oral tende a privilegiar um tipo de interação que, na comunicação à distância, tem poucas chances de ser bem sucedida. A teórica e praticante Valerie Yow (2014), por exemplo, em seu popular manual de história oral, afirma que, mesmo nos casos em que a comunicação à distância oferece imagem e voz, "perde-se muito": "[...] embora a imagem na tela ofereça pistas sociais, a escuta cuidadosa, sem pressa, profunda, e a busca intensa da entrevista em profundidade não são, em geral, facilitadas pela tecnologia do Skype" (YOW, 2014, p. 132). Sua observação é reflexo de uma tendência mais ampla: no âmbito da história oral, as entrevistas online costumam ser observadas com cautela, se não imediatamente descartadas, como se não houvesse dúvidas de que a história oral e a pesquisa em meio digital não são amigas, mas rivais.

Há diversas razões, no entanto, para que outros posicionamentos emerjam. A mais sonora delas é a potencial redução dos custos da pesquisa: nem sempre é possível dispor de financiamentos que permitam transpor barreiras geográficas, o que é crítico em pesquisas que envolvem entrevistas em vários estados ou países (ainda assim, excluindo potenciais entrevistados que não têm acesso fácil à tecnologia). Há também razões de cunho cultural. Relações sociais, pessoais ou institucionais vêm mudando substancialmente com os relacionamentos online ou mediados por máquinas. A presença física não é mais um critério de definição do que se considera uma relação social.

Talvez se possa afirmar que boa parte da resistência difusa ao uso de entrevistas online derive do fato de que a maior parte de nós - pesquisadores que utilizam o método da história oral, refletindo sistematicamente sobre as implicações de seu uso - formou-se e gestou suas próprias concepçóes acerca deste recurso de pesquisa dentro de uma estrutura de pensamento específica, que enfatiza o papel da interação presencial nas entrevistas. Por isso, podemos estar pouco propensos a reconhecer que os padróes estabelecidos como ideais para uma boa interação em história oral estejam sujeitos a mudanças. Embora o imbricamento entre a história oral e o desenvolvimento tecnológico seja claro (a ascensão desta prática dependeu, em boa medida, do aparecimento de aparelhos de gravação portátil, ao passo em que o advento do audiovisual impactou profundamente o entendimento da interação e da evidência em história oral), essa percepção parece congelada no tempo.

A eclosão da pandemia da COVID-19, no primeiro semestre do ano de 2020, parece ter acelerado uma revisão - que seria de todo modo inevitável - nesse cenário, como de resto em todos os campos sociais: as indústrias, as artes, as finanças, a política. Se o mundo dos negócios migrou quase instantaneamente para as soluções home office, no universo do ensino superior público ${ }^{4} \mathrm{e}$ da pesquisa, um prudente ceticismo rege as decisóes da maior parte das universidades ${ }^{5}$. Buscando contribuir para reflexóes pertinentes em um cenário como esse, apresentamos, neste artigo, uma reflexão sobre a possibilidade de realização de entrevistas conduzidas de acordo com os princípios da história oral no ambiente digital. 
Em um momento inicial, buscamos inserir o tema em uma problemática mais ampla: o lugar ocupado pelo corpo na história oral e em outros recursos de pesquisa correlatos. Já na segunda parte do artigo, procederemos a uma discussão sobre entrevistas online no terreno mais amplo do debate metodológico, evidenciando seu caráter fundamentalmente técnico, descritivo e circunstancial. Num terceiro momento, fazemos um breve relato de nossa própria experiência utilizando entrevistas online em diferentes projetos nos quais elas foram indispensáveis, assumindo que a ausência física do corpo não impede o êxito de uma entrevista. Tentamos extrair dessa experiência algumas sugestóes e recomendaçóes iniciais, que ainda deverão ser colocadas a teste por outros pesquisadores, compondo uma trama de diálogo mais espessa acerca dessa importante questão. Concluímos com uma apreciação dos recursos digitais preparados no calor da hora por grupos de pesquisa e associaçôes de história oral diante da pandemia da COVID-19, visando à orientação para a realização de entrevistas em um contexto de isolamento social.

\section{História oral, corpo e performance}

Um princípio tácito parece orientar a discussão metodológica no campo da história oral: a entrevista seria o encontro de duas subjetividades, de dois conjuntos de saberes, de dois repertórios linguísticos, etc., mas inclusive - e no meio de tudo isso - o encontro presencial de dois corpos. As palavras com que Jerusa Pires Ferreira finalizou um texto apresentado há bastante tempo, no 3o Encontro Nacional de História Oral, em 1996, são reveladoras do papel do corpo no pensamento sobre esse método de pesquisa: "[...] neste fim de século a grande riqueza da história oral é a comunicação em presença, a energia, o envolvimento multissensorial que inclui, entre outras, a categoria da fascinação” (1997, p. 66).

Mesmo na perspectiva do senso comum, é por meio do corpo que a entrevista de história oral acontece: pelo aparelho fonador, responsável pela produção vocal; pelo cérebro, onde a aquisição, o armazenamento e a evocação da memória se dão; pelos ouvidos, que detectam e processam os sons produzidos pelo interlocutor; pelos gestos, aliados não verbais na expressão de sensações, sentimentos, ideias; e assim por diante. Histórias orais são produzidas e veiculadas por um corpo e percebidas pelos sentidos de outro.

A centralidade desse ente na teoria da história oral se explicita no conceito de performance, ao qual Lynn Abrams dedica um capítulo inteiro de sua recopilação das bases teóricas e conceituais da história oral - o livro Oral History Theory, de 2010 -, alçando-o a uma posição equivalente à de "memória", "narrativa”, "subjetividade e intersubjetividade", "eu” [self], "poder e empoderamento". Para Abrams, essa eleição justifica-se pelo fato de que “[...] uma narrativa de história oral é, antes e acima de tudo, uma performance de palavras, uma maneira de falar separada da fala ordinária, um ato de fato performatizado para uma audiência em um contexto em particular” (ABRAMS, 2010, p. 130).

Em uma articulação sofisticada, embora não exaustiva, da literatura especializada, Abrams (2010, p. 130-131) revisita ideias e propostas que, a partir dos anos 1970, conformaram a história oral como um método interessado não apenas na fala, mas no falar; não apenas nos conteúdos manifestos, mas nas formas e nas performances da narrativa oral; nas palavras que eles [os entrevistados] escolhem, a cadência e o volume de sua fala, sua decisão de falar ou não no dialeto, o ritmo de sua narrativa; sem esquecer seus gestos, expressóes faciais e movimentos físicos, [que] são um elemento intrínseco da comunicação e contribuem para a interpretação feita pelo ouvinte das palavras e de seu significado. 
O motor e a armadura de todas essas peças - a autora reconhece - é o corpo, e esse reconhecimento tem implicações metodológicas bastante familiares à literatura instrucional da área. Guias e manuais chamam a atenção para as finuras da comunicação face a face: recomenda-se que os gestos e trejeitos, a força física, o olhar, o modo de se portar, a expressão facial do narrador, sejam cuidadosamente observados como subtextos capazes de certificar, complementar ou desdizer aquilo que um narrador conta verbalmente a respeito de si mesmo. Também se discute incessantemente como a presença física comunicada na fala poderia ser traduzida nas diversas técnicas de transcrição. Essa literatura instrucional chama atenção ainda para o ambiente no qual esse corpo se insere: o lugar de encontro sugerido ou determinado pelo entrevistado, o mobiliário e os objetos que o circundam em seu ambiente, para o modo como ele interage com o espaço. O corpo do próprio pesquisador torna-se objeto de preocupação e educação, já que sua presença mesma, em campo, é transformadora e construtiva - criadora de uma situação e de um produto, a narração e a narrativa, que não existem sem sua intervenção. Seria possível, então, - perguntamo-nos atônitos - separar a experiência narrativa dos corpos que a produzem? Podemos perguntar, ainda: a narrativa subjetiva pode construir-se com a interação não corporal? Se sim, qual o papel dessa interação não corporal (ou à distância ou virtual) na produção do relato e qual o seu impacto na memória?

Essas parecem ser as questôes de fundo para nós, pesquisadores de história oral, que informalmente lamentamos o esfacelamento de elementos cruciais quando da nossa prática em entrevistas online, mesmo que elas sejam construídas por meio de recursos audiovisuais (versus entrevistas telefônicas, centradas na dimensão auditiva) e síncronos (versus questionários respondidos por escrito ou outros instrumentos que não garantem simultaneidade na interação). A incipiência de discussões sobre entrevistas online - pelo menos até o presente momento - resulta, sem dúvida, do pressuposto pouco examinado de que a história oral só pode se realizar plenamente quando dois sujeitos se encontram corporalmente contíguos dentro de um mesmo espaço (físico e não virtual).

Uma situação de crise como aquela disparada globalmente com a pandemia da COVID19 pode nos instar a reconfigurar os sentidos de presença e ausência e suspender - mesmo que temporariamente - a compreensão de que eles estão necessariamente ligados à proximidade ou ao distanciamento físico/corporal. As reflexões de Lucia Santaella (2009) sobre a transformação das diferentes esferas da sociedade a partir da criação e do desenvolvimento de tecnologias de informação e comunicação ajudam-nos a reconsiderar esse imperativo. A comunicóloga e semioticista, que já defendeu a ideia do corpo como sintoma da cultura, vale-se do conceito de ressignificação para confrontar "[...] muitas das lamentaçôes sobre perdas das coordenadas físicas, das escalas de espaço e tempo, da propriocepção” (SANTAELLA, 2009, p. 123) que vêm à tona quando o estatuto do corpo humano, em sua inserção no ciberespaço, está em questão. Para a autora, lamúrias devem ceder lugar a uma compreensão aguda e crítica da evolução da ecologia midiática.

A argumentação de Santaella é estimulada pela conhecida proposição de Marshall McLuhan (1969), importante estudioso dos fenômenos comunicacionais em sociedade, de que os meios são prolongações do corpo humano (ou dos “meios de comunicação como extensões do homem”, em sua formulação linguística). Meios são entendidos aqui, frise-se, não como os meios de comunicação, mas como qualquer artefato tecnológico capaz de estender o corpo e acelerar seus sentidos, ampliando o domínio do humano sobre tudo aquilo que o rodeia. O surgimento de novos meios, afirmava McLuhan, seria capaz de transformar profundamente a sociedade e o humano, de formas imprevisíveis - impactando a percepção humana e engendrando novas sensibilidades. Criando a tecnologia, o ser humano é recriado por ela. 
Atenta à simbiose progressiva entre humanos e máquinas, à ideia (progressivamente mais real) de um ser humano ampliado pelas tecnologias, Santaella entende que a condição pós-humana coloca o homem diante de novos dilemas. Defendendo um pós-humanismo crítico, argumenta que "[...] as tecnologias atuais estão em uma linha de continuidade e representam uma crescente complexificação de um princípio que já se instalou de saída na instauração do humano" (SANTAELLA, 2007, p. 135) e dedica especial atenção àquilo que chama de tecnologia de fala. Ela escreve que “[...] certo estava Freud ao constatar, depois da virada dos anos 1920, que o ser falante é um animal desnaturalizado. A fala nos arranca do mundo natural e nos coloca, sem retorno possível, no artifício" (SANTAELLA, 2007, p. 135-136). E continua:

Falar não é natural. Natural é sugar, chupar, comer, respirar. Falar, cantar, beijar, chorar e rir são funções inseparáveis de um mesmo artifício, o artifício da maquinaria simbólica que está instalada em nosso próprio corpo. Dessa primeira maquinaria, de cuja fabricação não participamos, pois ela foi paradoxalmente instalada em nós pela natureza, todas as outras maquinarias, técnicas, artifícios ou tecnologias são prolongamentos, conforme venho argumentando há alguns anos [...]. a fala já é uma espécie de tecnologia, já é artificial. Depois da fala, vieram as escritas e todas as máquinas para a produção técnica de imagens, sons, audiovisuais e, atualmente, da hipermídia [...]. Essas tecnologias não são tão estranhas a nós quanto parecem ser. São prolongamentos do nosso corpo e da nossa mente. (SANTAELLA, 2007, p. 136)

Suas reflexões provocadoras instigam-nos a pensar nos novos modos perceptivos e cognitivos ativados na produção de entrevistas online, discrição cumulativa que não anula nem obscurece o encontro físico, analógico. Lembram-nos que uma entrevista, tal qual a conhecemos, é uma convenção circunstancial, não um artefato natural carente de fervorosa proteção. A entrevista - parafraseemos - já é artificial. E a comunicação - como quer que se dê - é sempre mediada. Um meio "frio" (McLUHAN, 1969) como a comunicação internética por vídeo pode, inclusive, preservar alguns de seus aspectos mais prezados: aciona simultaneamente vários dos sentidos dos interlocutores, potencializando a interação e requisitando-lhes maior carga de atividade; estabelece um ambiente ciberespacial no qual os corpos não são desmaterializados, mas reconfigurados virtualmente, por meio dos recursos disponibilizados pela tecnologia do momento.

Um único exemplo: sintomaticamente, à medida que a produção de conteúdo audiovisual televisivo durante a quarentena provocada pela pandemia da COVID-19 migrou para os lares e escritórios pessoais - posicionando a emissora como ponto de convergência e mediação, e não como espaço físico de produção -, novas sensibilidades afloraram e explicitaram-se. Reportagens e textos opinativos sobre os cenários nos quais jornalistas se posicionam são indicativas tanto de um fenômeno curioso quanto da percepção pública sobre ele, a saber: a performance mediatizada (BAUMAN, 2014) ou os processos de remediatização (BOLTER; GRUSIN, 2000) ativados por esses produtores de conteúdo, que se apropriam de valores e símbolos culturais (como paredes com obras de arte ou as estantes repletas de livros) na recomposição de sentidos de proximidade.

Sem dúvida, o assentamento do ambiente online como um espaço de interação e de produção de relatos de memória (como em exemplos que citaremos mais à frente) tem implicaçóes informadas tanto por rupturas quanto por continuidades. Ocorre que as primeiras tendem a ser mais sublinhadas que as segundas. Mudanças tecnológicas reorientam hábitos, costumes e práticas medulares para a comunicação humana; e novas modalidades de comunicação transfiguram gêneros do discurso, seus conteúdos e modos de dizê-lo. À história oral, felizmente incapacitada de 
se destacar do fluxo temporal, cabe apreciar criticamente tais mudanças, sem passar ao largo delas, propondo consideraçôes sobre a mudança efetiva no pensamento, na memória e na cultura a partir da incorporação de novas tecnologias, e sobre o impacto destas sobre a forma de se contar histórias.

\section{Pesquisa qualitativa e entrevistas online: passos em falso}

Ao passo que a possibilidade de interaçóes online é refutada com base na justificativa de que ela mutilaria os predicados de uma boa entrevista, suas vantagens são facilmente encobertas. Para mencionarmos apenas uma delas, lembremo-nos que em entrevistas online sequer precisamos utilizar gravadores de voz - objetos tão injustamente ocultados por alguns entrevistadores, que supervalorizam sua capacidade de intimidação dos entrevistados. A maior parte de nossas "vestes digitais", afinal, já possui dispositivos de gravação embutidos - como ouvidos estendidos capazes não apenas de escutar intensamente, mas também de documentar.

Um primeiro caminho para conhecer experiências no uso de entrevistas online é uma breve revisão bibliográfica, para além de nossa própria área, focalizando relatos de pesquisa nos quais o diálogo à distância - nem sempre qualificado como entrevista - é apreciado como uma ferramenta para coleta de dados, em interações audiovisuais síncronas, isto é, em tempo real. Estas são as que nos interessam, capacitadas para abrigar a substância de nosso trabalho, retendo aspectos críticos da entrevista de história oral: a oralidade (e com ela seus recursos expressivos, como a entonação, a qualidade vocal, entre outros), a imediatez (a narração e a escuta acontecendo em simultaneidade, garantindo a elaboração em tempo real dos relatos de memória, cuja reflexibilidade é constrita ao próprio desenrolar da entrevista), a dialogicidade (a possibilidade de reação e interferência e a flexibilização dos papéis desempenhados na entrevista), a situacionalidade (o acesso, mesmo que relativo, ao contexto no qual o narrador está inserido no momento da narração).

Um problema de base está no fato de que a maior parte dos relatos de experiência sobre diálogos online redunda na mera descrição de vantagens e desvantagens. Alguns chegam a enumerar como "problemas" ocorrências triviais, e até incontornáveis, como a interrupção de ligações devido a problemas técnicos ou de rede. Svensson et al. (2013), por exemplo, dedicam-se a avaliar a comunicação via Skype com cinco crianças portadoras de doenças crônicas. Após longa teorização sobre novas tecnologias, comunicação à distância e democratização tecnológica, as autoras descrevem seu estudo como uma intervenção na qual as crianças participariam de entrevistas abertas conversando com as pesquisadoras/tutoras sobre relacionamentos, emoções, direito à privacidade na família e na pré-escola. As autoras descrevem que seu objetivo é o de responder à pergunta "Que oportunidades e obstáculos surgem relacionados com a comunicação via Skype” (SVENSSON et al., 2013, p. 1021). Suas conclusões - baseadas naquilo que chamam de análise fenomenográfica resultam, pelo menos, óbvias: o levantamento de pontos positivos (a conveniência de estar em seu próprio ambiente, a possibilidade de que as partes vissem uma à outra através da câmera, o acesso ao suporte dos pais, a contribuição das famílias na apropriação da metodologia, a possibilidade de estar presente independente da distância geográfica) e negativos (a visualização e a audição limitada, a intermitência da conexão).

Escritos de outros autores seguem roteiro similar. Paul Hanna (2012) comenta sua experiência coletando entrevistas semiestruturadas para pesquisa de doutorado sobre turismo sustentável. Aludindo a Rappaport e Stewart (1997), afirma ter sido orientado por princípios da psicologia pós-estruturalista 
que teria entre suas metas oferecer aos participantes da pesquisa algum grau de controle sobre o processo de investigação. Esse princípio teria sido reiterado em função do tema abordado e dos entrevistados: viajar para conduzir entrevistas poderia conflitar com os princípios ecológicos dos participantes em relação ao transporte e à mudança climática. De fato, seis dos dezesseis entrevistados optaram por entrevistas por telefone e Skype, não desejando que "[...] uma viagem desnecessária tivesse impacto sobre o meio ambiente” (RAPPAPORT; STEWART, 1997, p. 240).

Hanna defendeu que as plataformas de comunicação consistem em um passo adiante na interação promovida por recursos como a sala de bate papo e que os aspectos visuais e interpessoais da interação não são perdidos. No entanto, indo na contramão de outros argumentos, chega a sugerir que as entrevistas telefônicas em áudio, sem vídeo, seriam também benéficas, já que levariam o pesquisador a permanecer no nível do texto, sem acrescentar informaçóes contextuais aos dados coletados - posição bastante controversa. Reconhecendo as limitações de sua experiência, Hanna sugere pesquisas futuras comparando os diferentes meios. Frisa, de qualquer forma, os ganhos trazidos por esse recurso: a diminuição de custos; a facilidade de acesso; a redução de dilemas ecológicos; a possibilidade de que as duas partes permanecessem em um "lugar seguro" e relativamente neutro, sem se "impor sobre o espaço pessoal do outro" (HANNA, 2012, p. 241).

Bertrand e Bourdeau (2010) discutem a realização de grupos focais à distância, apelando para os argumentos comuns da redução de custos, superação de longas distâncias e acessibilidade a um número maior de participantes. Também lhes parece positiva a possibilidade de análise dos movimentos corporais a partir de um mesmo protocolo metodológico, evitando os vieses inevitáveis às situações em que o observador transcreve suas impressóes para um diário de campo. No afã de justificar o uso dessa ferramenta, os autores adotam uma retórica exagerada, imprecisa e há muito criticada, afirmando que "[...] uma entrevista de pesquisa Skype-para-Skype é mais do que uma entrevista de pesquisa face-a-face [...] A entrevista gravada é um espelho do que ela foi na realidade” (BERTRAND; BOURDEAU, 2010, s.p.). Os achados que esses autores apresentam são menos reluzentes que seus propósitos, mas há alguns itens que merecem nota: a análise sobre o receio dos entrevistados e dos entrevistadores no uso da tecnologia; a importância da presença física na conquista de confiança; a virtualidade da entrevista como um fator facilitador que não desvia o entrevistado de sua rotina usual. Os pesquisadores também sugerem que a capacidade de visualizar, na tela, tanto o interlocutor quanto a si mesmo, leva os falantes a adquirirem maior ciência e controle sobre suas expressóes faciais; e, ao mesmo tempo, o impedimento da troca de olhares, devido ao fato de o narrador não olhar para o pesquisador, mas para a imagem dele na tela.

Em artigo de 2016, Seitz fez uma discussão sobre algumas questões técnicas de entrevistas por Skype, realizadas com 45 estudantes universitários. Para além dos óbvios tópicos sobre como driblar problemas práticos das entrevistas virtuais (quedas de conexão, trechos inaudíveis e outros) e das vantagens do uso dessa tecnologia para entrevistar pessoas distantes, a autora assinala que talvez o recurso virtual comprometa a leitura da linguagem corporal, tendo em vista os equipamentos não mostrarem o corpo integralmente. Para ela, uma maneira de contornar essa dificuldade seria prestar mais atenção às expressões faciais do entrevistado, intensificando as nossas próprias, e não descuidar do olho-no-olho. Ela discute ainda argumentos de outros autores sobre eventual perda da intimidade via Skype, mas enfatiza os ganhos em termos de novas informaçóes de pesquisa.

Seguindo os passos de outros autores, Deakin e Wakefield (2014) afirmam que o uso do Skype como ferramenta para entrevistas à distância alargou as possibilidades de pesquisa e que, apesar de contratempos práticos, pode ser um recurso útil para substituir entrevistas presenciais. 
Eles indagam como a comunicação virtual muda o que sabemos sobre a interação face-a-face, propondo que isso seja respondido no futuro. Uma observação dos pesquisadores diz respeito à especificidade das questóes éticas no ambiente virtual. O texto não aponta novidades em relação ao que foi visto nos trabalhos anteriores, limitando-se às indagaçóes mais técnicas do uso do Skype, em vez de inquirir como as relaçóes mudam no ambiente virtual e qual seria o seu impacto na construção de narrativas.

Outros autores perseguem inquietações específicas. Adams-Hutcheson e Longhurst (2017) preocupam-se com o papel do corpo do entrevistado e do pesquisador, baseando-se no conceito de "ritmo-análise", de Lefebvre. Eles afirmam que - ainda que as entrevistas por Skype reduzam as sensações proporcionadas pela proximidade física - as emoções pulsam ritmadas em qualquer espaço, em situaçốes online e offline, em pessoas e objetos. A partir da leitura de outros relatos, concluem que na maior parte das vezes os interlocutores se sentem desconfortáveis em interaçóes mediadas pelo computador, e chamam atenção para um aspecto pouco considerado na literatura metodológica: a multissensorialidade. "O Skype é um programa que as pessoas usam para se manterem 'em contato' e sentirem momentos tocantes. Elas não conseguem, porém, tocar fisicamente o outro ou os objetos representados na tela”, escrevem Adams-Hutcheson e Longhurst (2017, p. 152). Por outro lado, sugerem que a popularização gradual da interação virtual trará maior conforto a esse tipo de relação, criando novas formas de experimentar emoções e afetos no meio virtual.

Janghorban, Roudsari e Taghipour (2014) fizeram uma breve revisão de literatura em torno dos usos do Skype em entrevistas que serviram para pesquisas qualitativas como alternativa ou complementação ao diálogo presencial, reiterando a vantagem proporcionada pelo estreitamento das distâncias físicas. Citando Sullivan (2012), eles afirmam que "[...] o acesso a pistas verbais e não verbais em entrevistas por Skype pode oferecer um nível de autenticidade equivalente ao das entrevistas face-a-face, pois a oportunidade permite que uma parte visível do processo de gerenciamento da impressão seja avaliado” (SULLIVAN, 2012, s. p). E, baseando-se em outros autores, concluem que o anonimato relativo e a não participação de pesquisadores e entrevistados em uma rede social compartilhada "[...] pode aperfeiçoar a apresentação de si e a autenticidade, em comparação com entrevistas face-a-face" (SULLIVAN, 2012, s. p).

Conclusões como estas - vantagens e desvantagens e pormenores técnicos - podem soar desconcertantemente ingênuas, ou ao menos precipitadas, particularmente para o campo da história oral, herdeiro e praticante de uma reflexão sofisticada sobre as condiçóes de produção das entrevistas, atento à condição destas como "resíduo de uma ação interativa: a comunicação entre entrevistador e entrevistado" e "[...] resíduo de uma ação específica, qual seja, a de interpretar o passado” (ALBERTI, 2004, p. 35). A superficialidade de tais conclusóes talvez constitua, no entanto, uma condição necessária para sua própria superação - e preferível a ocasiões em que os pesquisadores pressupóem uma equivalência entre encontros presenciais e diálogos à distância, apenas mencionando de maneira trivial o caráter de suas interaçóes.

Ao fim e ao cabo, respostas pragmáticas - oriundas de todo o amplo espectro de posicionamentos no continuum do entusiasmo tecnológico - são importantes, desde que apontem na direção do que está para além delas. Diante de uma possibilidade de se conseguir uma entrevista indispensável no modo online, mas não no presencial, deve-se descartá-la, por não cumprir as expectativas da interação corpo-a-corpo? Em uma pesquisa com mulheres trabalhadoras e mulheres vivendo com HIV/Aids, a equipe dirigida por Luciana Kind e Rosineide Cordeiro concluiu acertadamente que 
não: "Antes de rechaçar as entrevistas realizadas por Skype ou por telefone, assumimos os riscos de produção de entrevistas nessas condições, considerando suas idiossincrasias", escrevem Luciana Kind e Rosineide Cordeiro (2016, p. 314). Não se furtaram, no entanto, a asseverar tratar-se de um “[...] importante material narrativo que atende aos objetos da investigação" (2016, p. 315), merecedor de uma discussão específica. À medida que o número de estudos sobre coleta de dados em interações à distância, síncronas, através de videoconferência, cresça, espera-se ser possível extrair, deles, proposições passíveis de generalização visando a apontar a superação das dificuldades com os quatro critérios críticos da entrevista com história oral, mencionados anteriormente: oralidade, imediatez, dialogicidade e situacionalidade.

\section{História oral e pesquisa de campo digital: experiências e lições}

Nessa direção, buscamos relatar brevemente experiências de pesquisa, claramente identificadas com a perspectiva da história oral - portanto, atentas ao caráter oral, memorial, relacional e performativo das entrevistas. Nessas pesquisas, parte das entrevistas foi coletada à distância, por meio eletrônico, exigindo dos participantes - tanto os narradores quanto os pesquisadores - formas de envolvimento e aproximação não usuais, por vezes inéditas. Cabe ponderar, reforçando o que dissemos anteriormente, que as lições de pesquisa trazidas por casos como esses são pontuais e, como projetos coletivos assumidos por uma comunidade acadêmica, deverão desejavelmente ser cruzadas com outras experiências no futuro.

Em dois projetos recentemente conduzidos por Valéria B. Magalhães, uma das autoras deste artigo, foram combinadas entrevistas virtuais com entrevistas presenciais. A opção não se deu por comodismo, pois teria sido deveras interessante e desejável a interação presencial, mas à impossibilidade de se chegar pessoalmente a alguns dos entrevistados. Em ambas as pesquisas, entretanto, não seria justificável descartar a oportunidade de entrevistas, apenas por serem feitas à distância. Não se podia correr o risco de ignorar a riqueza dos relatos gravados virtualmente nem a importância que alguns entrevistados atribuíam às suas próprias histórias e versões.

Em uma primeira situação, entrevistas com imigrantes brasileiros foram conduzidas presencialmente nos Estados Unidos com financiamento do $\mathrm{CNPq}^{6}$. Durante quatorze dias na Flórida, foram entrevistadas dezesseis pessoas. Entretanto, alguns dos encontros não foram possíveis devido à agenda dos narradores, que aceitaram (e alguns até propuseram) a entrevista à distância. Essas foram realizadas após o retorno da pesquisadora ao Brasil. Em outro momento, em uma pesquisa recente que visava a analisar o uso da história oral em pesquisas sobre migraçóes internas, foram feitas entrevistas temáticas com pesquisadores sobre suas trajetórias profissionais. Boa parte delas aconteceu presencialmente em São Paulo, no Rio de Janeiro e em estados do Nordeste, contando o projeto com financiamento da Fapesp ${ }^{7}$. Algumas, todavia, escaparam aos recursos financeiros disponíveis, mas não poderiam deixar de ser feitas, tendo em vista a relevância das trajetórias dos entrevistados para o projeto. Assim, foram realizadas virtualmente, tendo trazido ótimos resultados para a análise do tema investigado.

Do ponto de vista metodológico, foi possível observar a importância de alguns cuidados técnicos para uma entrevista à distância. Em primeiro lugar, uma maior atenção à qualidade da gravação do áudio, tendo em vista que o som pode se dispersar na interação mediada pelo computador, gerando ruídos desnecessários. Outro cuidado é garantir ao entrevistado toda a informação 
possível sobre o pesquisador e sobre o projeto de pesquisa, de modo que ele fique assegurado em relação à confiabilidade do projeto e à idoneidade do entrevistador. Além disso, é necessário que se combine com o entrevistado a forma de autorização de uso, seja ela gravada (como no caso desses projetos) ou assinada e escaneada, para garantir futuros usos. Uma recomendação que julgamos importante em gravaçóes à distância é que sempre seja enviada uma cópia dela ao narrador, garantindo a transparência sobre o conteúdo do seu relato. Em relação ao aspecto do corpo-a-corpo mediado pelo recurso virtual, os diálogos mostraram-se confortáveis, íntimos e frutíferos para todas as partes e não houve manifestação de que havia algum problema no diálogo mediado. A dialogicidade e situacionalidade da comunicação foi mantida. Não se perceberam diferenças, em termos puramente conteudísticos, entre esses depoimentos e os outros relatos ouvidos presencialmente pela pesquisadora.

Em uma pesquisa de história oral com mulheres brasileiras, em que se reentrevistou narradoras que haviam sido gravadas três décadas antes pela pesquisadora americana Daphne Patai, o outro autor deste artigo, Ricardo Santhiago, necessitou recorrer pontualmente à entrevista online. ${ }^{8}$ Tratava-se de uma pesquisa histórico-biográfica que buscava fazer uma leitura comparativa de narrações oferecidas em diferentes momentos da vida; por essa razão, as entrevistadas não eram permutáveis. Uma das mais importantes do projeto havia se mudado para uma pequena cidade no interior do Texas - o que não se sabia antes do planejamento de pesquisa. Na impossibilidade de efetuar uma viagem com o fim exclusivo de entrevistá-la, sua história foi coletada, por sua sugestão, por meio do Skype - recurso utilizado por ela diariamente para se comunicar com a família e com amigos. A entrevista foi surpreendentemente aberta e produtiva, realizando-se em três sessões de cerca de uma hora, a pedido da própria narradora. Acostumada a interações online, ela afirmou perder a concentração e se cansar, depois de passar esse intervalo de tempo diante do computador. Além de ser uma importante lição prática, útil para outras entrevistas, apresentou a percepção da própria entrevistada, sobre a ação à distância mediada tecnologicamente, como um fenômeno que age de maneira distinta sobre o corpo. A reconstituição do diálogo diante da tela, a concentração intensa e constante exigida em um meio "frio" como o computador - conforme propunha McLuhan (1969; 2018) - aumentam a tensão comunicacional, possuindo implicações evidentes sobre um colóquio, reconhecidas pela própria narradora.

Em uma pesquisa coordenada por Santhiago, realizada dentro de uma disciplina de metodologia de pesquisa realizada em um curso de graduação em Fonoaudiologia, os alunos gravaram entrevistas de história oral como forma de experimentar uma ferramenta particularmente útil pedagogicamente por condensar habilidades exigidas por outros instrumentos. ${ }^{9}$ Em um projeto coletivo, os alunos deveriam fazer entrevistas de história oral com egressos das primeiras turmas, que haviam se formado cerca de dez anos antes. Tendo em vista que depois de sua graduação esses egressos haviam retornado às suas cidades de origem ou se mudado, em busca de colocação profissional, e que o caráter integral do curso dos alunos oferecia pouco tempo livre para a realização das entrevistas, os relatos à distância foram uma saída instantaneamente aventada - de um modo tão natural que, neste caso, coube ao docente orientar os alunos no sentido oposto: o de desnaturalizar as entrevistas à distância, refletindo sobre as suas implicaçóes. Em um grupo de 36 alunos, cerca de metade optou por cada um dos recursos. Nas rodas em que as experiências foram discutidas, era impossível distinguir quem havia feito entrevistas online e quem havia estado em encontros presenciais: esse corte não causava distinção em termos de intensidade, envolvimento e 
aproveitamento, deixando à espreita o binômio presencial/à distância como um corte a ser percebido superficialmente. Sem dúvida, isso está ligado também ao aspecto geracional: além de serem alunos predominantemente nascidos entre 1999 e 2000, obtiveram sua formação intelectual em um momento no qual os recursos digitais já estavam bastante assimilados no contexto do ensino superior. $\mathrm{O}$ aspecto geracional, aliás, certamente é um fator importante para o conforto ou não com esse tipo de contato na pesquisa.

Essas quatro experiências em que nos envolvemos com entrevistas à distância levaram - para nossa surpresa - a resultados positivos. No entanto, não tiveram nem terão caráter substitutivo, nem encaminham uma defesa de seu uso indiscriminado. A mera conveniência do pesquisador, por exemplo, não deve ser tomada como justificativa plausível para sua adoção. Porém, as novas tecnologias não podem ser ignoradas, sobretudo em situações nas quais consistem na única forma de viabilização da pesquisa. O recurso virtual deve ser entendido como mais uma ferramenta a aproximar entrevistador e entrevistado, um recurso de coligação útil, um caminho para o entendimento das complexas interações e dos pontos de vista sobre a história que não estariam disponíveis de outra forma.

Sem objetivar uma descrição exaustiva, podemos apontar alguns itens importantes a serem considerados - além daqueles que já foram mencionados - em projetos nos quais a entrevista online seja indispensável:

1. Entrevistas feitas à distância são mais promissoras quando não apenas os entrevistadores, mas também os entrevistados, possuem aptidão e intimidade com os recursos de videoconferência. Estes recursos estendem a função que o telefone desempenhou no passado, encurtando distâncias e permitindo a construção e a manutenção de laços afetivos, se for o caso. Não deve escapar ao pesquisador sua inserção em uma cultura em que aplicativos e plataformas interconectam indivíduos, inclusive viabilizando novas relações de amizade, amor e sexo. De certa forma, a preocupação com a perda de intimidade encetada pela entrevista online evidencia uma ênfase excessiva na ideia - na maioria dos casos contrariada pela prática - de que toda e qualquer entrevista constrói uma relação de intimidade entre narrador e pesquisador (e aí a ideia de que a presença física do corpo seria determinante talvez para o sucesso dessa intimidade). Será que ambos, de fato, criam na entrevista uma relação de compartilhamento de um cotidiano e de uma experiência psíquica e corporal comuns? E, se sim, qual seria o impacto disso na construção do relato de memória, na evocação das lembranças? Pode-se argumentar que em muitas situações um grau menor de intimidade pode tornar a entrevista mais confortável para o entrevistado. ${ }^{10}$ A suposição de que intimidade e compromisso respeitoso com o outro são equivalentes talvez esteja na base da reticência à entrevista feita à distância. Não serão a proximidade ou o distanciamento físico que garantirão a confiança mútua em uma pesquisa;

2. Em todo caso, os momentos de pré-entrevista podem fortalecer o relacionamento entre entrevistado e entrevistador e orientar uma relação de cordialidade, respeito e profissionalismo e de explicitação das expectativas em relação à presença física ou à mediação da internet. Ela também é o momento de explicitação e negociação sobre os aspectos técnicos, como o software ou a plataforma utilizada; a fonte de gravação (sempre que possível, deve-se solicitar ao entrevistado gravar sua própria voz, a fim de contornar 
problemas de conexão ou compreensão); a discussão sobre o meio pelo qual a cessão e autorização de uso da entrevista serão concedidas; entre outros aspectos;

3. É importante ter clareza acerca do potencial e dos limites interpretativos do trabalho sobre relatos oferecidos online. A sedução da visualidade como um aspecto distintivo, por exemplo, deve ser requalificada à luz de dois aspectos. Em primeiro lugar, as imagens em movimento possibilitadas por videoconferência são planas e enquadradas pelo narrador; em segundo lugar, em toda e qualquer pesquisa, a introdução de elementos visuais demanda ferramentas de análise e interpretação específicas, distintas das que viabilizam a leitura e o aproveitamento de materiais verbais;

4. A cibercultura possui uma ambiência própria e hábitos de comunicação particulares, que privilegiam a interação e a participação, por um lado, mas que criam a propensão à brevidade, por outro. Textos e vídeos produzidos para o universo digital costumam ser abreviados; a entrevista deve ser igualmente aclimatada, a fim de não conduzir à desatenção, já que a presença online prolongada pode levar ao comportamento multitarefas. Em uma análise sobre a investigação digital, a praticante de história oral Rachel Rettaliata desencorajou entrevistas longas contando que, em dois casos, “[...] o entrevistador chegou a ouvir os sons de um videogame sendo jogado pelo entrevistado enquanto a entrevista estava acontecendo" ${ }^{11}$. Em lugar disso, a divisão da gravação em várias sessões pode ser uma saída.

\section{A pandemia da COVID-19 e as entrevistas à distância: reações imediatas da história oral}

Nos últimos anos, o campo da história oral - em sua justaposição com as mais diversas perspectivas interdisciplinares - tem agudizado sua atenção às situações de crise e intensificado a busca de soluções que aperfeiçoem sua capacidade de reagir rapidamente a crises sociais, preocupando-se também com a combinação da documentação imediata e da produção de conhecimento crítico. Linhas de fomento, publicações e eventos têm corporificado essa atenção (RODRIGUES; BORGES; SANTHIAGO, 2020). A crise global da COVID-19 - qualificada pela Organização Mundial da Saúde(OMS) como pandemia, em março de 2020 -, com suas consequências imediatas e com previsão de duradoura repercussão social, cultural e econômica, apresenta um desafio de vulto único, mesmo no interior dessas reflexões.

Dentre as diferentes iniciativas imediatas tangentes à prática da história oral está a criação de bancos de dados para o depósito de histórias, ancorados na história pública, como as plataformas Covid-19 Memories, criada pelo Centro de História Contemporânea e Digital da Universidade de Luxemburgo ${ }^{12}$, coronarchiv, ${ }^{13}$ que consorcia professores de três universidades alemãs, sob os auspícios da Universidade de Hamburgo, e Corona Archive, da Universidade Kansai, no Japão ${ }^{14}$. Pensadas como arquivos digitais crowdsourced - nas quais as figuras do produtor e do colecionador são corpos virtuais coletivos, e seus objetos são predominantemente nato-digitais -, essas iniciativas colocam questôes interessantes a respeito das implicações estéticas e políticas do que José Luis de Vicente (2014) chamou de "produção social de dados”. Para a problemática do presente artigo, porém, interessam especialmente as iniciativas ligadas à instrução metodológica para realização 
de entrevistas online durante os períodos de quarentena e restrição de convívio social (que inviabilizam diálogos presenciais), seja para discutir a experiência sob a pandemia, seja para iniciar ou dar continuidade a projetos de documentação e pesquisa sobre outros temas.

O Vermont Folklife Center - organização de folcloristas que registram e preservam a memória cultural do estado do Vermont - criou o projeto Listening in Place, tendo entre seus objetivos a criação cooperativa de um arquivo sonoro sobre as experiências cotidianas das pessoas durante a pandemia. ${ }^{15}$ Entre os recursos disponibilizados, está um breve guia com sugestóes técnicas para a escolha de plataformas de realização e softwares de gravação de videoconferências; e outro guia sugerindo as precauçóes para entrevistas presenciais com pessoas que já estejam no mesmo espaço. Pressupondo que a escuta pode ser um "caminho para atravessar a ansiedade, o medo, a incerteza", o centro dirige-se a uma comunidade ampliada de sujeitos, para além dos pesquisadores profissionais, buscando criar situaçóes para o compartilhamento de experiências e o acolhimento da alteridade. A propósito, além do arquivo sonoro com histórias orais, o centro vem trabalhando também com a criação de rodas de histórias virtuais. Em um caminho parecido, a Associação de Historiadores Públicos do Estado de Nova York lançou em 29 de março de 2020 uma lista de instruçôes acompanhando a recomendação de que os historiadores trabalhassem para documentar em tempo real o impacto da COVID-19, com sugestões para a produção de diários, registros fotográficos, colecionamento de notícias, além da realização de entrevistas de história oral. ${ }^{16}$ Já o Washington Post - apoiando-se numa tradução que entende a história oral como uma espécie de gênero textual e editorial, não refratário à estetização - lançou em 15 de abril de 2020 o multimídia Uma história oral da pandemia de coronavirus, com testemunhos transcritos e em áudio, acompanhados por fotografias e vídeos curtos, recolhidos por sua equipe. ${ }^{17}$ Essas iniciativas - valiosas como reações rápidas da história oral, em sua vertente pública - consistem em sua maioria em sugestóes procedimentais pontuais e de pouca envergadura reflexiva, estando, todavia, em conformidade com o próprio entendimento de história oral e de história pública, como métodos de distribuição social da interpretação das experiências humanas, que perseguem. Devem, por isso, ser observadas com cautela.

$\mathrm{Na}$ esfera mais propriamente acadêmica, pelo menos dois centros de história oral desenvolveram oficinas específicas. História oral dos desastres e pandemias foi apresentada por Mary Marshall Clark, diretora do Centro de Pesquisa em História Oral da Universidade Columbia, afinada à temática dos desastres. ${ }^{18}$ Ela dirigiu um projeto de pesquisa longitudinal (entre 2001 e 2005) com cerca de 650 entrevistas com indivíduos afetados pelos ataques de 11 de setembro de 2001 - que resultou no livro After the Fall: New Yorkers Remember September 2001 and the years that followed (CLARK et al., 2016) - e integra a equipe de pesquisa de uma investigação sobre o papel das enfermeiras no surto de ebola na África Ocidental entre 2013 e 2016. A fala mesclou os relatos dessas investigações com comentários metodológicos sobre as estratégias de pesquisa adotadas.

Já o Instituto de História Oral da Universidade Baylor e a Associação de História Oral americana, associaram-se em um webinar conduzido por Adrienne Cain, Steven Sielaff e Stephen Sloan ${ }^{19}$ - o último, frise-se, coorganizador com Mark Cave de um dos livros mais importantes da área na última década, Listening on the Edge: Oral History and Crisis (CAVE; SLOAN, 2014), que discute o papel da história oral em situações de tragédias naturais e conflitos sociais. Ponderada e complexa, a oficina iluminou as diferentes camadas sobre as quais entrevistas à distância se assentam, em três partes, enfatizando, na primeira delas, as questóes éticas e jurídicas comuns e peculiares (incluindo a assinatura digital de termos de cessão). De maneira procedente, a oficina 
sugeriu a pré-entrevista - sequer mencionada nos trabalhos a que aludimos na seção dois, por ser mais comum nas situações de maior envolvimento pessoal, pela narrativa - como um recurso crucial para as entrevistas online. Ela teria não apenas a função de que já dispõe nas entrevistas presenciais (a obtenção de informações necessárias para a construção do roteiro, a criação de uma relação de familiaridade e empatia, a discussão dos aspectos procedimentais e legais), mas também seria o momento ideal para a checagem das dificuldades técnicas, para a avaliação ambiental, para a orientação do narrador no tocante ao uso da plataforma ou do software adotado.

A terceira parte da oficina lidou com os aspectos propriamente técnicos da gravação de entrevistas feitas por telefone ou videoconferência, com sugestóes de equipamentos e formatos, em diferentes estágios de investimento. Levantou a questão importante da segurança de gravações processadas por terceiros e armazenadas em nuvens - fundamental para a preservação de dados delicados, cuja distribuição deva ser discutida ou controlada. E a segunda parte, conduzida por Sloan, que lidou com a relação entre entrevistador e entrevistado, apresentou um ponto notável: "[...] estudos sobre entrevistas à distância extraem conclusôes conflitantes sobre se o formato à distância realça fenômenos como dizer a verdade ou lidar com tópicos sensíveis”, conforme uma súmula escrita do seminário registrou. ${ }^{20}$ Talvez essa conclusão deva ser expandida, de fato, para toda a discussão sobre a produção e o uso de entrevistas feitas à distância - que, embora venha sendo aperfeiçoada e adensada à luz dos reflexos da COVID-19, permanece longe de qualquer consenso.

A Oral History Society, sociedade britânica de história oral, lançou um comunicado mais conservador, intitulado Conselhos sobre a realização de entrevistas de história oral durante a pandemia da COVID-19. ${ }^{21} \mathrm{O}$ documento reflete o esforço de seus quatro autores em reunir bibliografia sobre entrevistas à distância em tempo de crise, em propor soluçôes tecnológicas, em apontar dilemas procedimentais e éticos. No entanto, reflete também uma oportuna prudência, convidando os pesquisadores de história oral a ponderar sobre a urgência da entrevista, a prioridade para um indivíduo do oferecimento de seu testemunho em meio a um cotidiano de estresse e anormalidade, o estado mental do próprio pesquisador e sua capacidade de executar adequadamente as tarefas que precedem e sucedem a entrevista. A entidade enfatiza que a temporalidade das atividades de pesquisa já foi impactada pela pandemia, como demonstram a extensão de prazos para pós-graduandos e a suspensão dos calendários de agências de fomento. Recomendando que as entrevistas presenciais sejam, sempre que possível, adiadas, em vez de substituídas por conversas à distância, a instituição esboça alternativas possíveis à adesão afoita às entrevistas online. A assunção da provisoriedade desse guia - cuja segunda versão, a mais recente até a finalização do presente artigo, foi publicada em 31 de maio de 2020 - é um indicador do caráter provisório e em processo das liçôes que os efeitos sociais da pandemia da COVID-19 têm oferecido, em velocidade acelerada, à pesquisa digital.

\section{Mais perguntas, menos respostas}

Como se vê, não existem conclusóes únicas e definitivas acerca da legitimidade e do valor da aproximação entre a história oral e os recursos para a preparação, gravação e o armazenamento de entrevistas à distância, em ambiente digital. $\mathrm{O}$ debate a seu respeito e as experiências de pesquisa - postergado e evitado na discussão metodológica - estão apenas abertos, em função da situação de isolamento social, de limitação de movimentos, de suspensão de atividades, de transformação 
das condiçóes de trabalho ensejada pela pandemia da COVID-19. O presente artigo apresentou-se, assim, como uma contribuição inicial e situada de nossa parte.

Em um artigo sobre história oral e tecnologia, o pesquisador Leland McCleary (2011) defendeu que os pesquisadores baseados na universidade (instituição informada por dois influxos simultâneos, um em favor do passado, da preservação do conhecimento, e outro em favor do futuro, do avanço do conhecimento) devem questionar até que ponto caminham de costas para o futuro "[...] porque seu pensamento foi matrizado pelos artefatos e conhecimentos de ontem e até que ponto os novos olhares, propiciados pelas novas tecnologias, lhe dão ferramentas para reavaliar o modo de pensar já consolidado” (McCLEARY, 2011, p. 95). Essa observação, feita há uma década, parece inteiramente válida para os dilemas muito atuais acerca da entrevista online.

Em lugar de uma forqueadura partida entre a euforia adesista e a recusa absoluta a um tipo de história oral supostamente deformado (pela ausência da interação corpo-a-corpo), devem colocar-se experiências empíricas de entrevistas online, discussões técnicas e procedimentais, debates teóricos e filosóficos vários, todos eles vigiados pelos princípios basilares da história oral: o compromisso com a criação e a preservação de novas fontes, a atenção e o respeito ao entrevistado, a garantia de pluralidade de pontos de vista na pesquisa, a compreensão das implicações das circunstâncias de produção sobre a fonte, e assim por diante. Em práticas profissional e eticamente responsáveis, essas premissas não serão rompidas, seja em ambiente real ou virtual.

Discordamos, portanto, da afirmação de $\mathrm{Yow}^{22}$, apresentada no início deste artigo, de que "perde-se muito" nas entrevistas à distância e de que a busca pela profundidade na entrevista se perderia com a entrevista por Skype. O que nos parece é que, apesar de muitas questóes ainda não terem sido respondidas, a entrevista virtualmente conduzida pode ser frutífera e até necessária, desde que as condições de sua produção sejam discutidas metodologicamente em termos de como elas impactaram o resultado final do relato.

Há, sem dúvida, muitas outras novas questões a se considerar: como é que questôes de confiabilidade, de autenticidade, de ética, de privacidade, etc., traduzem-se e renovam-se no ambiente online? Como os instrumentos de comunicação online servem a propósitos de vigilância e controle? Como pensar questóes novas e específicas sobre segurança, arquivamento e sigilo na Internet? Como decisões metodológicas tomadas em situação de crise podem alimentar mudanças institucionais profundas com as quais não concordaríamos sob outras circunstâncias? Sejam quais forem as respostas a essas perguntas, serão elaboradas porque assumem que a entrevista é, e continuará sendo, um encontro valioso, imprevisível e quase sempre surpreendente entre dois sujeitos.

\section{Referências}

ABRAMS, Lynn. Oral History Theory. Abingdon: Routledge, 2010.

ADAMS-HUTCHESON, Gail; LONGHURST, Robyn. At least in person there would have been a cup of tea: interviewing via Skype. Area, v. 49, p. 148-55, 2017.

ALBERTI, Verena. O que documenta a fonte oral: a ação da memória. In: Ouvir Contar: Textos em História Oral. Rio de Janeiro: Editora FGV, 2004.

BAUMAN, Richard. Fundamentos da performance. Sociedade e Estado, v. 29, n. 3, p. 727-46, 2014.

BERTRAND, Catherine; BORDEAU, Laurent. Research Interviews by Skype: A New Data Collection Method. In: ESTEVES, José (org.). Proceedings from the $9^{\text {th }}$ European Conference on Research Methods. Spain: IE Business School, 2010. p. 70-79. 
BOLTER, Jay David; GRUSIN, Richard. Remediation: Understanding New Media. Cambridge: The MIT Press, 2000.

CAVE, Mark; SLOAN, Steven M. (org.). Listening on the Edge: Oral History and Crisis. New York: Oxford University Press, 2014.

CLARK, Mary Marshall et al. (org.). After the Fall: New Yorkers Remember September 2001 and the Years That Followed. New York: The New Press, 2016.

DEAKIN, Hannah; WAKEFIELD, Kelly. Skype Interviewing: Reflections of Two PhD Researchers. Qualitative Research, v. 14, n. 5, p. 603-16, 2014.

HANNA, Paul. Using Internet Technologies (Such as Skype) as a Research Medium: A Research Note. Qualitative Research, v. 12, n. 2, p. 239-242, 2012.

HOLT, Amanda. Using telephones for narrative interviewing: a research note. Qualitative Research, v. 10, p. 113-121, 2010.

JANGHORBAN, Roksana; ROUDSARI, Robab Latifnejad; TAGHIPOUR, Ali. Skype interviewing: The new generation of online synchronous interview in qualitative research. International Journal of Qualitative Studies on Health and Well-being, v. 9, 2014.

KIND, Luciana; CORDEIRO, Rosineide. Os encontros: quem compõem o ofício de pesquisar. Athenea Digital, v. 16, n. 2, p. 307-324, 2016.

MCCLEARY, Leland. História oral: Questões de língua e tecnologia. In: SANTHIAGO, Ricardo; MAGALHÃES, Valéria Barbosa de (org.). Memória e diálogo: Escutas da Zona Leste, visões sobre a história oral. São Paulo: Letra e Voz, 2011. p. 93-123.

McLUHAN, Marshall. Os meios de comunicação como extensões do homem. São Paulo: Cultrix, 1969.

McLUHAN, Marshall. O meio é a mensagem [1967, com Quentin Fiore]. São Paulo: Ubu Editora, 2018.

PIRES FERREIRA, Jerusa. Os desafios da voz viva. In: VON SIMSON, Olga Rodrigues de Moraes (org.). Os desafios contemporâneos da história oral. Campinas: Centro de Memória Unicamp, 1997. p. 59-68.

RAPPAPORT, Julian; STEWART, Eric. A critical look at critical psychology: elaborating the questions. In: FOX, Dennis; PRILLELTENSKY, Isaac (orgs.). Critical Psychology: An introduction. London: Sage, 1997.

RODRIGUES, Rogério Rosa; BORGES, Viviane Trindade; SANTHIAGO, Ricardo. O devir público da história no tempo presente: outras linguagens, outras narrativas. Manuscrito não publicado, 2020.

SANTAELLA, Lucia. Pós-humano - Por quê? Revista USP, n. 74, p. 126-37, 2007.

SANTAELLA, Lucia. Da cultura das mídias à cibercultura: o advento do pós-humano. Revista FAMECOS, n. 22, p. 23-32, 2003

SANTAELLA, Lucia. Revisitando o corpo na era das mobilidades. In: LEMOS, André; JOSGRILBERT, Fábio (org.). Comunicação e mobilidade aspectos socioculturais das tecnologias móveis de comunicação no Brasil. Salvador: EDUFBA, 2009. p. 123-36.

SEITZ, Sally. Pixilated Partnerships, Overcoming Obstacles in Qualitative Interviews via Skype: A Research Note. Qualitative Research, v. 16, n. 2, p. 229-35, 2016.

SULLIVAN, Jessica R. Skype: An appropriate method of data collection for qualitative interviews? The Hilltop Review, v. 6, p. 54-60, 2012.

SVENSSON, Agneta et al. Experiences of Skype communication in education and research: data collection concerning young children with long-term illness. Early Child Development and Care. 2014.

VICENTE, José Luis de. Armazenando o eu: Sobre a produção social de dados. In: BEIGUELMAN, Giselle; MAGALHÃES, Ana Gonçalves. Futuros possíveis: arte, museus e arquivos digitais. São Paulo: Peirópolis: Edusp, 2014. p. 288-301.

YOW, Valerie R. Recording Oral History: A Guide for the Humanities and Social Sciences. Lanham, MD: Rowman \& Littlefield, 2014. 


\section{Notas}

${ }^{1}$ HUNT, Jennifer. Using Skype for interviews. 24 de outubro de 2014. Disponível em: https://networks.h-net.org/node/16738/ discussions/49947/using-skype-interviews\#reply-49999. Acesso em: 12 set. 2019.

${ }^{2}$ Menciona-se frequentemente o Skype por se tratar de uma plataforma antiga, com versão em software (lançada em 2003) e consolidada (principalmente desde 2011, quando foi vendido para a Microsoft e integrado a uma série de outros produtos e serviços oferecidos pela empresa, substituindo no catálogo da empresa o antigo Messenger). O Skype continua sendo o recurso líder para comunicação online através de voz e vídeo, apesar da crescente concorrência (como o Hangouts, do Google, e o Facebook Video Call, entre outros sistemas). De modo geral, os argumentos aplicam-se a todas as outras soluções tecnológicas semelhantes.

${ }^{3}$ Disponível em: https://networks.h-net.org/node/16738/discussions/49947/using-skype-interviews\#reply-49999. Acesso em: 23 jun. 2020.

${ }^{4}$ Em alguns casos, tal ceticismo encaminha orientações aparentemente paradoxais: na Universidade Federal de São Paulo, a Pró-Reitoria de Pós-Graduação e Pesquisa recomendou o cancelamento imediato de toda e qualquer "atividade prática", mencionando nominalmente "entrevistas" e "coleta de dados". Poucos dias depois, sua Pró-Reitoria de Extensão e Cultura aconselhou a "reinvenção" de atividades extensionistas, estimulando a intensificação de ações no ambiente digital, como "diálogos virtuais". Tomados em conjunto, os dois comunicados desta universidade sugerem uma incerteza no tocante a ações institucionais diante da pandemia - incerteza difusa, da qual este é um exemplo próximos entre outros possíveis. Mas eles apontam também para a necessidade de persecução de discussões metodológicas que acompanhem a agilidade do rebentamento de questões socialmente relevantes e urgentes. (Disponível em: https://coronavirus.unifesp.br/. Acesso em 13 abr. 2020). No caso da Universidade de São Paulo, as orientações da Pró-Reitoria de Pesquisa não mencionam especificamente o caso das entrevistas, mas dizem que as "atividades de pesquisa de campo devem ser evitadas nesse período" (Pró-Reitoria de Pesquisa USP. COVID-19 - Orientações da Pró-Reitoria de Pesquisa USP. 19/mar/2020. Disponivel em: https://coronavirus.usp.br/wp-content/uploads/sites/707/2020/03/orientacoes_PRP_coronavirus_19032020. pdf. Acesso em 13 abr. 2020). Em relação às aulas, a Reitoria estabeleceu, assim que o isolamento foi determinado pelas instâncias governamentais, que a continuidade das aulas se daria à distância em todas as disciplinas em que isso fosse possível, utilizando as ferramentas online da própria universidade, tais como Moodle e-disciplinas e Tidia (Moodle e-disciplinas: https://edisciplinas.usp.br/acessar/. Tidia-ae: https://ae4.tidia-ae.usp.br/portal)

${ }^{5}$ Sobre a situação das universidades privadas e escolas, recomenda-se a leitura de: CÁSSIO, Fernando; XIMENES, Salomão. Coronavírus e a 'volta às aulas'. Le Monde Diplomatique, 31 mar. 2020. Disponível em: https://diplomatique.org.br/ coronavirus-e-a-volta-as-aulas/. Acesso em: 9 abr. 2020.

${ }^{6}$ Projeto O Brasil no Sul da Flórida: diversidade e memória, coordenado por Valéria B. Magalhães e financiado pelo CNPq (2013-2018).

${ }^{7}$ Projeto Nordestinos em São Paulo e História Oral: abordagem histórico-crítica, coordenado por Valéria B. Magalhães e financiado pela Fapesp (2018-2020)

${ }^{8}$ Projeto $A$ mulher brasileira fala, 30 anos depois: memória, intersubjetividade, método, coordenado por Ricardo Santhiago, financiado pelo CNPq (2014-2018).

${ }^{9}$ Projeto Experiências e trajetórias de egressos do Curso de Fonoaudiologia da Unicamp, coordenado por Ricardo Santhiago e desenvolvido na disciplina Metodologia de Pesquisa II do curso de graduação em Fonoaudiologia e continuado como grupo de estudo (2016-2017).

${ }^{10}$ Em reunião recente com orientandos, Valéria B. Magalhães perguntou como eles se sentiriam se tivessem que realizar entrevistas por Skype e se achavam que a ausência de contato físico atrapalharia a interação. A maior parte mostrou-se confortável com isso, mas outros (inclusive a orientadora) argumentaram que não se sentem tão à vontade com o contato físico com estranhos e que a distância até poderia ser interessante. Temos ainda que considerar que talvez alguns dos entrevistados também possam preferir uma entrevista que não envolva o toque e, principalmente, que não adentre seus espaços pessoais, tais como sua casa e o próprio espaço corporal. (Reunião ocorrida em novembro de 2019, nas dependências da EACH/USP, contando com orientandos de pós-graduação, iniciação científica e pós-doutorado).

${ }^{11}$ Disponível em: http://rachelrettaliata.org/digital-history/oral-history. Acesso em: 20 dez. 2018.

${ }^{12}$ Disponível em: https://covidmemory.lu/. Acesso em: 15 abr. 2020.

${ }^{13}$ Disponivel em: https://coronarchiv.geschichte.uni-hamburg.de/. Acesso em:15 abr. 2020. Sobre este projeto, ver também a postagem de Thorsten Logge no blog da editora De Gruyter. Disponivel em: https://blog.degruyter.com/coronarchiv-how-public-historians-are-collecting-memories-of-the-corona-pandemic/. Acesso em: 15 abr. 2020.

${ }^{14}$ Disponível em: https://www.annex.ku-orcas.kansai-u.ac.jp/covid19archive. Acesso em: 19 abr. 2020. 
${ }^{15}$ Disponivel em: https://www.vermontfolklifecenter.org/listening. Acesso em: 15 abr. 2020.

${ }^{16}$ Disponível em: http://www.aphnys.org/historians-start-documenting-covid-19/. Acesso em: 17 abr. 2020.

${ }^{17}$ Disponível em: https://www.washingtonpost.com/graphics/2020/national/coronavirus-oral-history. Acesso em: 17 abr. 2020.

${ }^{18}$ A oficina aconteceu no dia dezesseis de abril de 2020 , sendo transmitida pela plataforma Zoom.

19 O webinar aconteceu no dia 31 de março de 2020, sendo posteriormente disponibilizado no YouTube. Disponível em: https://www.youtube.com/watch?v=WsSTWkVTitO. Acesso em: 15 abr. 2020.

${ }^{20}$ Disponível em: https://www.oralhistory.org/wp-content/uploads/2020/04/Oral-History-at-a-Distance-Summary.pdf. Acesso em: 17 abr. 2020

${ }^{21}$ Disponível em: https://www.ohs.org.uk/advice/covid-19/. Acesso em: 17 abr. 2020.

22 "Embora a imagem na tela ofereça pistas sociais, a escuta cuidadosa, sem pressa, profunda, e a busca intensa da entrevista em profundidade não são, em geral, facilitadas pela tecnologia do Skype" (YOW, 2014, p. 132).

Recebido em: 22/04/2020

Aprovado em: 13/06/2020 